\title{
Electrospinning of polyacrylonitrile (PAN) solution: Effect of conductive additive and filler on the process
}

\author{
P. Heikkilä̈ ${ }^{*}$, A. Harlin ${ }^{2}$ \\ ${ }^{1}$ Department of Materials Science, Tampere University of Technology, P.O. Box 589, FI-33101 Tampere, Finland \\ ${ }^{2}$ VTT Technical Research Centre of Finland, P.O. Box 1000, FI-02044 VTT, Finland
}

Received 25 February 2009; accepted in revised form 23 April 2009

\begin{abstract}
Electrospinning utilizes electric forces and hence the electrical properties of the solution have an effect the process. The study examined the effect of conductive additive and filler on the electrospinning process with polyacrylonitrile (PAN). Electrospinning trials were performed using a pure PAN solution, a salt-containing solution, and a solution containing carbon nanotubes (CNTs). Different nozzle sizes were used, and the spinning voltage and distance were also varied. The composition of the solution had a greater effect on fibre diameter than varying the process parameters. Conductivity of the solution increased the probability of process problems such as the formation of three-dimensional (3D) structures and the occurrence of larger, micro-sized fibres. When the viscosity of the solution was increased, as was the case with the PAN/CNT solution, the severity of the problems became less acute than with the PAN/Salt solution.
\end{abstract}

Keywords: nanocomposites, electrospinning, polyacrylonitrile, nanofibres, conductive additives

\section{Introduction}

Sub-micron and nanofibres can be prepared from a polymer solution utilizing electrospinning [1-5]. In electrospinning, the electrostatic field stretches the polymer solution into fibres as the solvent is evaporating. During the process the polymer jet undergoes instabilities, which together with the solution properties, determines the morphology of the forming nano-sized structures obtained onto the collector [6-8]. The instabilities are caused by two opposing forces that affect the jet as follows: 1) the surface tension, which stabilizes the jet and tends to minimize its surface; and 2) the charge repulsion, which destabilizes the jet and increases its surface [9]. Three distinguishable competing instability modes can occur: 1) a classical (axisymmetric) Rayleigh break-up instability mode, 2) an axisymmetric conducting instability mode; and 3) a whipping conducting instability mode $[10,11]$, also known as bending instability $[12,13]$. Numerous solution and process variables affect these instabilities. Conducting modes, especially whipping, are enhanced with increased voltage and electric field strength, while Rayleigh instability is suppressed by them $[6,10]$.

Electrospun fibres can be functionalized by the use of additives, and fillers of many kinds can be used to form composite fibres $[14,15]$. The properties of electrospun fibres can be modified using nanosized fillers. Carbon nanotubes (CNTs) are widely used as filler in electrospun fibres [16-29]. Typically, their function is to serve as a reinforcement component [16-19] in electrospun polymeric fibres, but they are also used to modify the electrical properties of fibres [20-23].

The use of filler in the solution may affect the different properties of the solution. The filler particles may, for example, act as charge carriers which 
cause the conductivity of the solution to increase the charge density of the jet and, thereby, enhance instabilities. Charge carriers such as salts or conductive filler particles have an influence on the conductivity of the solution and they may promote two phenomena having opposite effects on fibre formation and diameter [8]. Firstly, they may increase flow rate, which can lead to larger fibres [30]. Secondly, they may increase net charge density, which suppresses the Rayleigh instability and enhances the whipping instability, leading to the formation of bead-free fibres and smaller fibre diameter [31]. In addition, additives may affect the interactions in the solution and thus also have an effect on fibre diameter and morphology [8].

Salts and other conductive additives have been found to reduce $[32,33]$ and also increase fibre diameter [30, 34]. Ju et al. [24] and $\mathrm{Ra}$ et al. [23] obtained finer fibres with CNT-containing solution compared to a CNT-free one. It was also observed that beads formed especially when CNT concentration was high or the dispersion of the CNTs in solution was poor [23]. Mathew et al. [35], on the other hand, found that CNTs led to broader fibre diameter distribution and especially the occurrence of fibres having larger diameters. According to the authors this can be explained by the increase in solution viscosity or by the creation of new interfaces between polymer and CNTs [35]. The effect of fillers and additives on fibre diameter varies from system to system depending on the polymer, solvent as well as the additive $[8,36]$.

Fillers and additives may also interact with solvent, with polymer or with both. The electrospinnability of the solution may also change as a result of these interactions, but it may also remain unchanged, regardless of the additive. [8] It has, for example, been shown [36] that conductive solutions can form different kinds of three-dimensional (3D) loose structures on the substrate, instead of a thin coating layer attached to the substrate surface. The form of these structures can vary from fibrils perpendicular to the substrate surface to a fluffy layer of cottonlike structure. Fibrils can even extend to cover the entire electrospinning zone. If this kind of conductive fibrous structure connects nozzle and plate, the electric field discharges and the process stops [36, 37]. The optimization of process parameters for ternary systems can be even more challenging than for binary systems composed only of polymer and solvent [8].

This study examined the phenomena caused by conductivity. Polyacrylonitrile (PAN), whose behaviour in electrospinning is well known [30, 38-41], was used in the experiments. Electrospun PAN fibres have many possible applications, one of which is the production of carbon nanofibres (CNF) by carbonization of electrospun precursor fibres $[17,21,25,26,29,40-45]$. CNTs can be used in precursor fibres since CNT filler may effectively resist heat shrinkage in composite fibres during the carbonization process [29]. CNTs may have a positive effect on crystallinity and the order of polymer [25] and the presence of CNTs may also promote the growth of carbon crystals during PAN carbonization [26]. Since the addition of CNT has an effect on the viscosity of the solution, the conductivity of polymer solution was also modified with salt, for comparison. Process parameters such as voltage, distance, and nozzle size were varied in order to determine the optimum process for each solution. The study observed and evaluated the functioning of the electrospinning process as well as the quality of electrospun web.

\section{Experimental}

\subsection{Materials}

Spinning solutions of pure PAN and salt-containing PAN were prepared by dissolving polymer (13 wt \%) in heated DMF. The solution was heated and stirred until the polymer dissolved, after which $\mathrm{ZnCl}_{2}$ salt $(0.25 \mathrm{wt} \%)$ was dissolved into salt-containing polymer solution. Dispersing of CNTs evenly into pure DMF or into viscous polymer solution is a difficult process, and so the composite solution was prepared in three steps. First, a small amount of PAN was dissolved in DMF because this acts as a dispersing agent. Then CNTs $(0.25 \mathrm{wt} \%$, MWCNT NC7000 from Nanocyl S.A., average diameter $9.5 \mathrm{~nm}$, average length $1.5 \mu \mathrm{m}$ ) were added and dispersed in dilute polymer solution by ultrasonic homogenizing. Finally, the rest of the polymer was added to achieve the desired polymer concentration (13 wt \%). Dispersion of CNTs in solution prepared this way has been found to be relatively good, even though some agglomerates might still be present [46]. 


\subsection{Electrospinning experiments}

Electrospinning was performed using continuous process equipment in which a horizontal electric field was generated between a nozzle system and a collector plate (Figure 1a). A web having a width of $300 \mathrm{~mm}$ was conveyed past the front side of the collector. The nozzle system used in the trials was composed of one tube having places for ten nozzles. A metal rod within the tube was connected to the voltage source (Simco Chargemaster BP 50) from one end of the tube. The solution was fed from the opposite end of the tube, and nitrogen gas with controlled pressure was attached to the feeding system of the tubes. The collector plate was connected to ground. The fibres were collected on paper and metal grid substrates, which were attached onto nonwoven web.

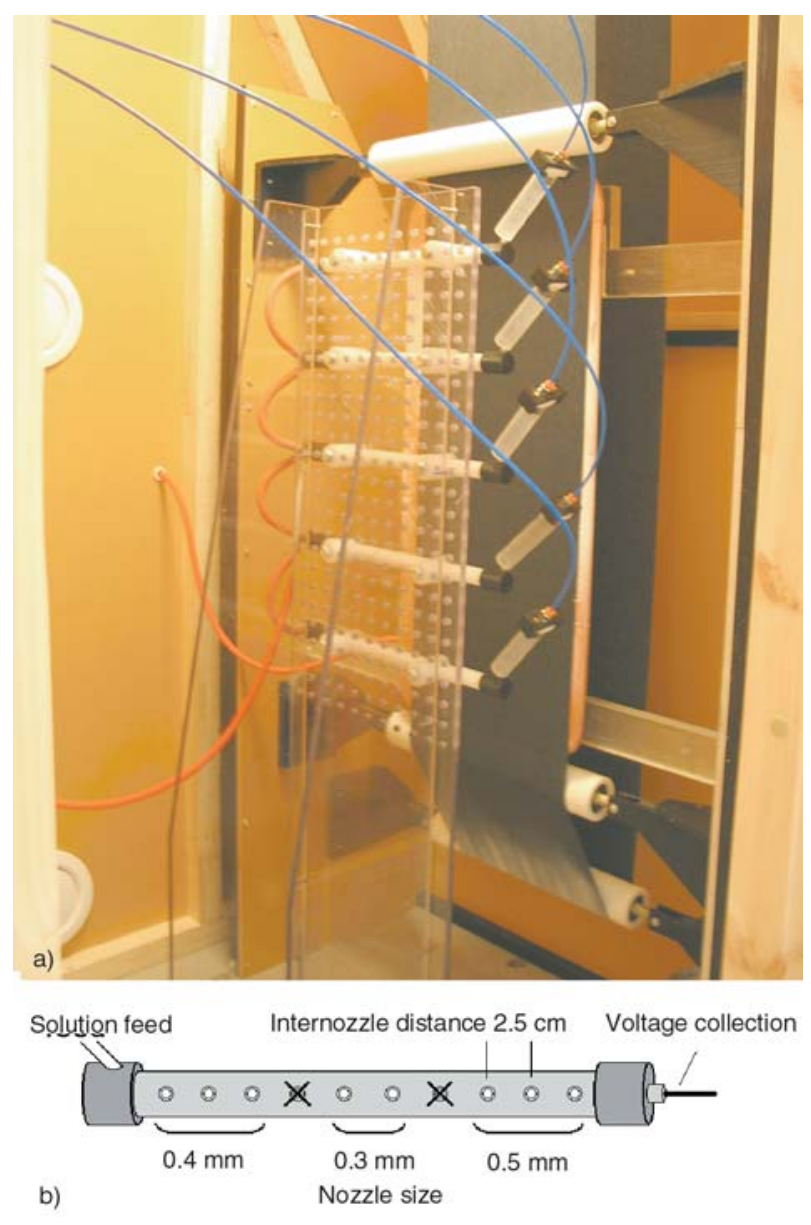

Figure 1. a) Electrospinning equipment equipped with five tubes: a horizontal electric field is generated between the nozzle system and the collector plate and a web is conveyed past the collector. b) Nozzle arrangement on one tube used in this study. Nozzle diameter on the left was $0.4 \mathrm{~mm}$, in the middle $0.3 \mathrm{~mm}$ and on the right $0.5 \mathrm{~mm}-$ two nozzle places were blocked.
Samples were prepared by conveying substrates at a fixed line speed through the electrospinning zone. Three nozzle sizes were used. Each of three right side nozzles was $0.5 \mathrm{~mm}$ in internal diameter and each of the two middle and three left side nozzles was 0.3 and $0.4 \mathrm{~mm}$ respectively, two nozzle places were blocked (Figure 1b). Each nozzle formed a stripe of fibre on the substrate (stripes on the substrate are in reverse order to the nozzles on the tube). Two distances, $100 \mathrm{~mm}(S)$ and $150 \mathrm{~mm}(L)$, were used in electrospinning trials. The voltage was varied $(10-40 \mathrm{kV})$ so that electric field strengths in the trials measured 67, 133, 200 and $267 \mathrm{kV} / \mathrm{m}$.

\subsection{Characterization}

Conductivity of the solution was measured with Schott Instruments, Handylab LF11. Viscosity was measured with Brookfield DV-II + viscometer. The production rate and the quality of the fibrous coating were evaluated from photographed samples. SEM imaging was used to observe fibre quality and Philips XL30 and Zeiss Ultra Plus SEM equipment was used to determine the fibre diameter of selected samples. Image Tool 3.0 software was used for diameter measurements from SEM images. Over 100 measurements were made at each trial, and mean diameter $[\mathrm{nm}]$ and its standard deviation [nm] were also calculated.

\section{Results and discussion}

\subsection{Formation of electrospun web}

Conductivity of PAN solution was $115 \mu \mathrm{S} / \mathrm{cm}$ while the conductivity of the PAN/Salt and PAN/ CNT solutions were higher: 196 and $158 \mu \mathrm{S} / \mathrm{cm}$, respectively. The viscosity of both the PAN and PAN/Salt solutions was around $1150 \mathrm{mPa} \cdot \mathrm{s}$, while the viscosity of the PAN/CNT solution was around $4650 \mathrm{mPa} \cdot \mathrm{s}$. Due to this difference in viscosity optimum nozzle size varied. Solutions having lower viscosity dripped from the largest nozzle, while those with higher viscosity could barely flow through the smallest nozzles. Dripping of solution was more pronounced at low electric field strengths. Short distance seems to increase the dripping tendency even with constant electric field strength, though this may be partially attributable to the horizontal arrangement of the field. The amount of droplets may remain unchanged, but a longer dis- 


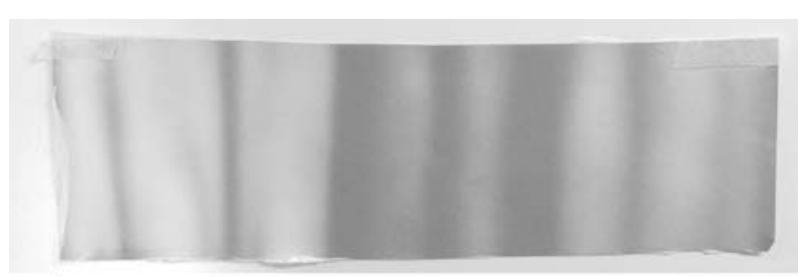

a)

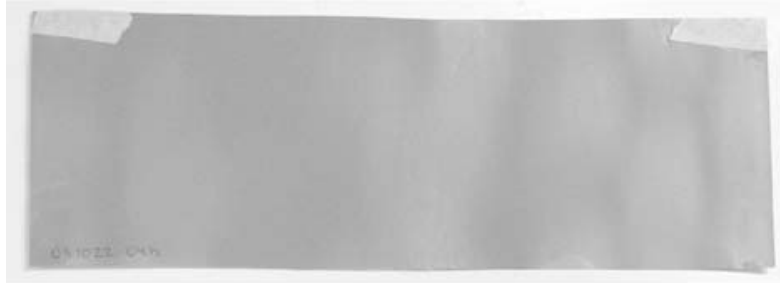

b)

Figure 2. Appearance of white PAN nanofibre stripes on dark paper: a) $40 \mathrm{kV} / 150 \mathrm{~mm}$, b) $10 \mathrm{kV} / 150 \mathrm{~mm}$. Nozzle size on the left was $0.5 \mathrm{~mm}$, in the middle $0.3 \mathrm{~mm}$ and on the right $0.4 \mathrm{~mm}$. Higher voltage and larger nozzle size increased the amount of fibres on substrate.

tance may increase the likelihood that the droplet trajectory does not reach the substrate. Overall the 0.4 nozzles were best for PAN and PAN/Salt solutions and the 0.5 nozzles for the PAN/CNT solution since they enable sufficient solution flow and thus, relatively high productivity. Besides nozzle size, electric field strength had a significant effect on productivity. The effect of nozzle size and voltage on the amount of fibres can be seen in Figure 2.

The electrospinning process usually produces a smooth fibre layer fixed on the surface of the sub-

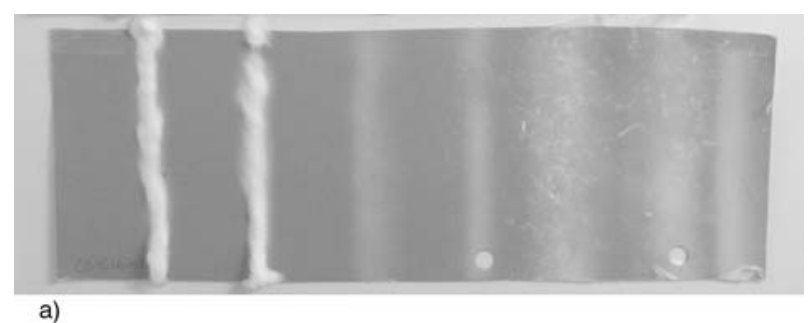

a)

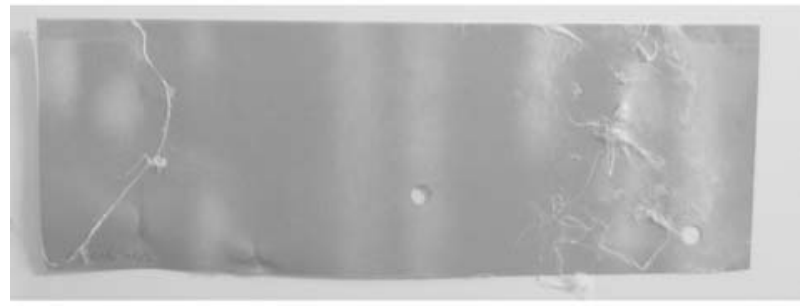

b)

Figure 3. Appearance of white PAN/Salt nanofibre stripes on dark paper: a) $40 \mathrm{kV} / 150 \mathrm{~mm}$, b) $20 \mathrm{kV} / 100 \mathrm{~mm}$. Nozzle size: left $0.5 \mathrm{~mm}$, middle $0.3 \mathrm{~mm}$ and right $0.4 \mathrm{~mm}$. Inclusion of salt increased the occurrence of 3D fibre structures and visible fibre bundles. strate, but the fibres made of conducting PAN/Salt solution often produced fluffy cotton-like 3D structures or otherwise loose fibre structures on top of the substrate (Figure 3). These structures can be considered as defects from a production point of view. Another slightly less disruptive defect, which occurred in association with $3 \mathrm{D}$, was the formation of larger fibres or fibre bundles visible to the naked eye. Pure PAN solution and PAN/CNT composite solutions produced 3D structures and visible fibre bundles on paper only at the highest voltages and shortest distances. The formation of 3D structures with PAN/Salt fibres was also more pronounced at higher voltages.

Occurrence with high conductivity and high voltage indicated that 3D structures would be induced by high electrical forces. This is supported by our finding that use of a conductive metallic grid as a substrate increases the probability of 3D structures, especially with PAN/Salt and PAN/CNT solutions. PAN/Salt and PAN/CNT solutions differed in 3D tendency even though they contained conductive component. This can, however, be explained by the fact that PAN/CNT solution had high viscosity, which tends to stabilize the process and also reduce the flow of the solution. Short distance seemed to increase 3D tendency even at constant electric field strength, but this might be attributed to reduced stretching and the larger diameter of the jet, and thus a larger charge density on the surface of the jet and larger electric forces affecting it. Electrical forces are not, however, the only factors affecting the occurrence of this tendency, since large nozzle size also increased 3D structures. High electrical forces and large nozzle size both have an increased effect on solution flow rate, which in addition to electrical forces, seem to contribute to the occurrence of 3D structures.

\subsection{Electrospun fibres}

The composition of the solution affected the diameters and appearance of the fibres. The appearance of PAN, PAN/Salt and PAN/CNT fibres electrospun under the same conditions (voltage $20 \mathrm{kV}$, distance $150 \mathrm{~mm}$, nozzle $0.4 \mathrm{~mm}$ ) are exemplified in Figures 4a-4c. In PAN/CNT composite fibres, filler showed more pronounced surface roughness and markedly larger fibre diameters than the PAN and PAN/Salt fibres. Surface roughness is a typi- 


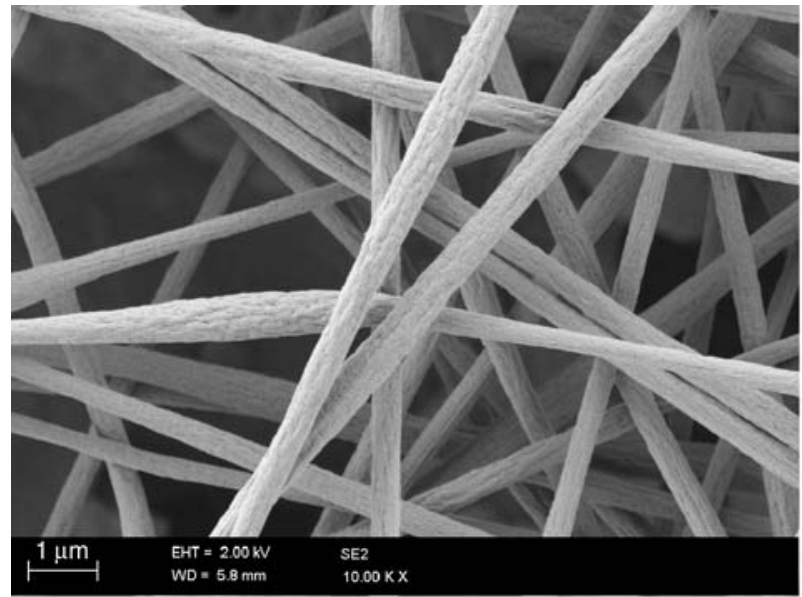

a)

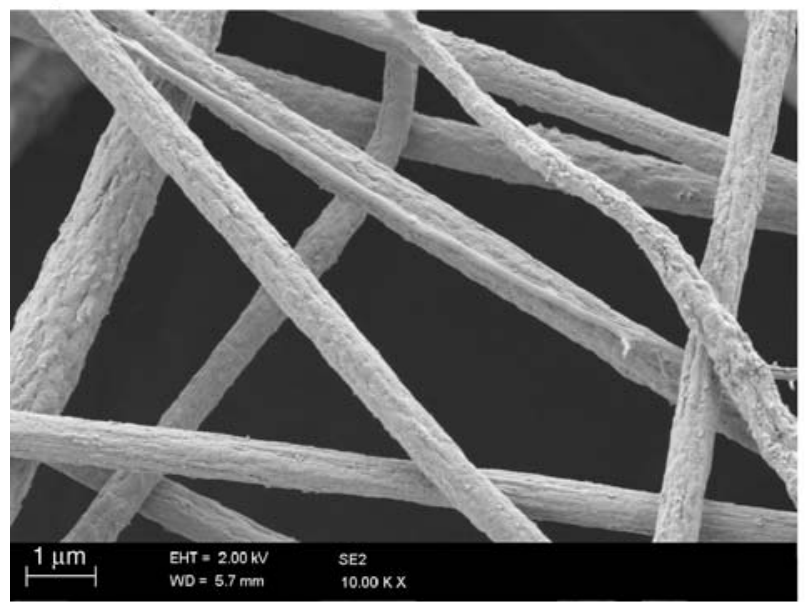

c)

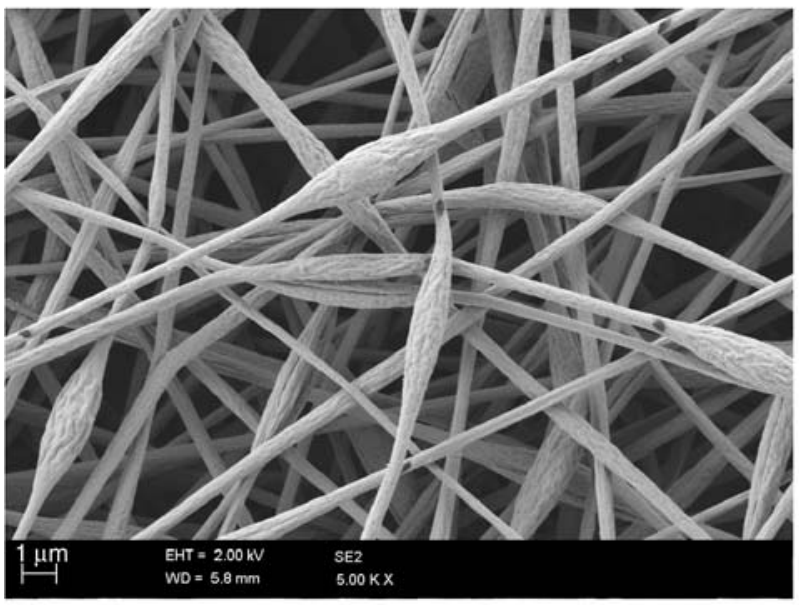

e)

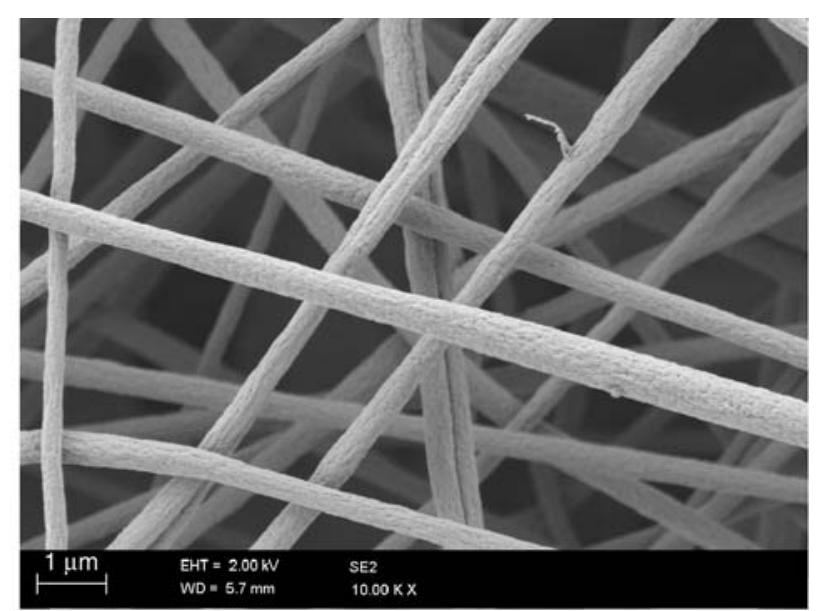

b)

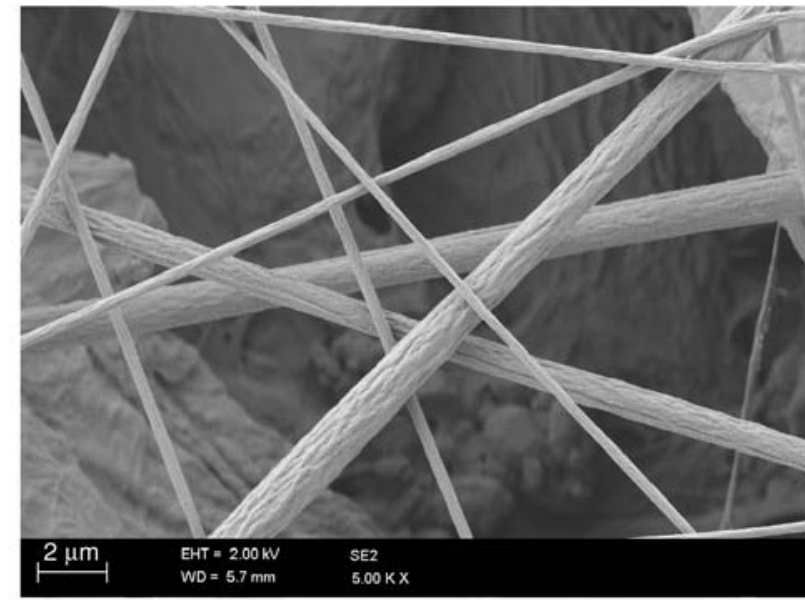

d)

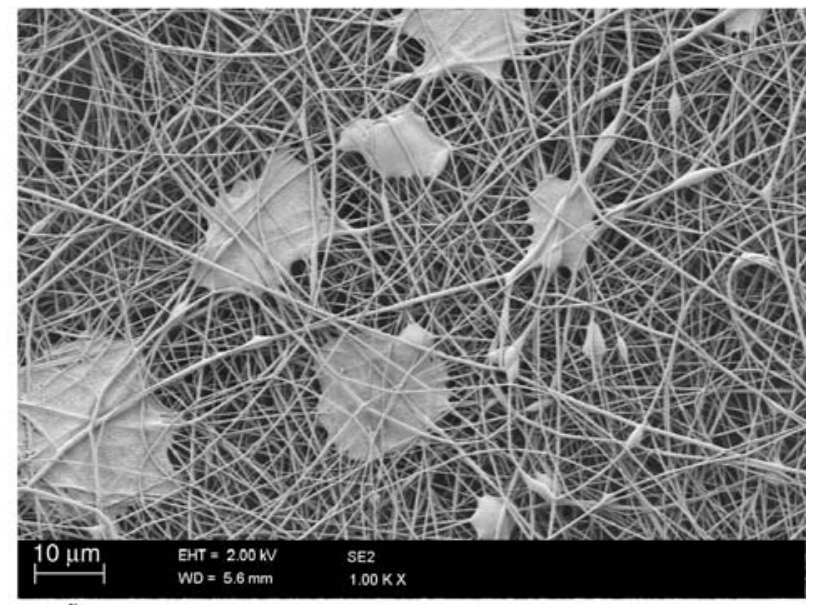

f)

Figure 4. Appearance of a) PAN, b) PAN/Salt and c) PAN/CNT fibres electrospun (voltage $20 \mathrm{kV}$, distance $150 \mathrm{~mm}$, nozzle $0.4 \mathrm{~mm}$ ) (magnification in SEM imaging 10000×), d) bimodal fibre distribution composed of two distinctive fibre diameter ranges (SEM 5000×), e) beaded fibres (SEM 5000×), and f) larger fibres and micro sized solution splatters (SEM 1000×).

cally observed characteristic of CNT composite fibres [23, 24], and increased fibre diameter can be explained by increased viscosity [35]. The difference in viscosity is the reason for the difference in the fibre diameter of PAN/CNT and PAN/Salt solu- tions even though the conductivities of the solutions were nearly at the same level.

In addition to 3D structures, certain other imperfections were observed. In some trials with small nozzles and low field strength we also observed that 
the PAN and PAN/Salt solutions produced a clear bimodal fibre diameter distribution (Figure 4d). Spindle-shaped beads (Figure 4e) occurred occasionally with PAN and PAN/Salt solution in trials conducted using shorter distance $(100 \mathrm{~mm})$. Other defects observed in the electrospun webs were enlarged fibres and micro-sized solution splatters (Figure 4f). While larger fibres were regularly observed with the PAN/Salt solution, their occurrence with PAN and PAN/CNT solutions was mainly limited to cases where the distance was short or the electric field strength was high.

The dependence of fibre diameter on solution composition is illustrated in Figure 5. PAN/Salt fibres had a slightly larger diameter than PAN fibres, in contrast to the conventional view that a more conductive solution causes a reduction in diameter [32]. In this case higher conductivity seems to have led to increased mass flow and thus larger fibre diameters. Our findings are consistent with those of Qin et al. [30]. In their studies on the effect of different salts on the electrospinning of PAN, they observed that salt, which has the greatest effect on conductivity, also produced fibres with the largest diameters. Slightly varying diameters in fibres typically occurs with the use of fillers [8]. However, this variation in individual fibre diameter had no effect on the standard deviation of fibre diameter. In general, solution composition had greater influence on fibre diameter than either spinning distance or strength of the electric field. Gu et al. [41] have also reported that voltage is not a significant factor in determining the diameter of PAN fibres. The differences in the diameters of fibres prepared using a single solution in different spinning distances and

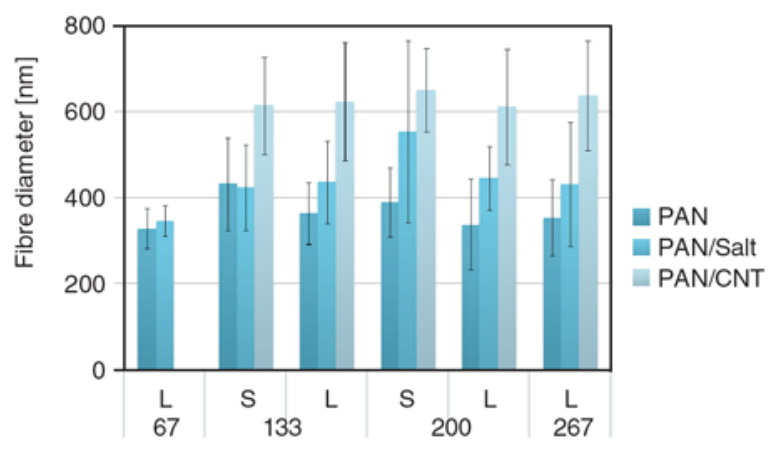

Figure 5. Fibre diameters of PAN, PNA/Salt and PAN/CNT solutions electrospun using $0.4 \mathrm{~mm}$ nozzles. Spinning distances $(S=100 \mathrm{~mm}$ and $L=150 \mathrm{~mm}$ ) and electric field strengths $[\mathrm{kV} / \mathrm{m}]$ are presented in $x$-axis.

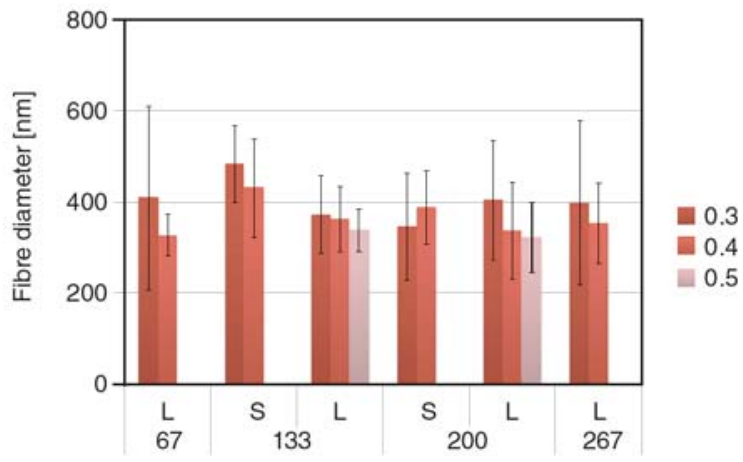

Figure 6. Fibre diameters of PAN solution electrospun using different nozzle sizes $(0.3 \mathrm{~mm}, 0.4 \mathrm{~mm}$ and $0.5 \mathrm{~mm})$. Spinning distances $(S=100 \mathrm{~mm}$ and $L=150 \mathrm{~mm}$ ) and electric field strengths $[\mathrm{kV} / \mathrm{m}]$ are presented in $x$-axis.

electric field strengths were not significant, though a slight trend could be detected (Figure 5). If electric field strength remained constant, and the distance was increased, fibre diameters were slightly decreased. Longer distance enables greater stretching of the solution jet. Although fibre diameters can be expected to decrease in the presence of a stronger electric field due to increased stretching, our studies showed no evidence for such a trend. An increase in electrical force can produce contradictory effects since it can increase both whipping instability and mass flow [36].

The effect of nozzle diameter with PAN solution is illustrated in Figure 6. Somewhat surprisingly, the fibre diameters produced from larger nozzles were often smaller than those from smaller nozzles, even though such differences were statistically insignificant. We suggest that this tendency is because the more stable spinning process obtained with larger nozzles might promote an adequate and continuous solution flow. This view is also supported by the finding that there was less variation in fibre diameter when larger nozzles were used.

\section{Conclusions}

This study demonstrated the electrospinning of PAN solutions with salt as the conductive additive, and CNTs as conductive filler. Parameters such as voltage, distance, and nozzle size, were varied. The quality of the electrospun web and the fibres was studied, as well as the functioning of the process.

The PAN and PAN/Salt solutions had similar viscosity but the PAN/Salt solution produced slightly larger fibres because increased conductivity 
enhanced the mass flow. The higher conductivity of the PAN/Salt solution increased the instabilities in the electrospinning process. This was also the most probable cause of the increased process problems, such as the formation of 3D structures and defects in fibrous web such as larger fibres. These phenomena were less common with PAN/CNT solution, which also contains a conductive component. The conductivity of the PAN/Salt solution was higher than that of the PAN/CNT solution. The addition of CNTs in the solution also had a significant impact on the viscosity of the solution, which tends to stabilize the process. As expected, increased viscosity gave rise to larger fibre diameters compared to PAN and PAN/Salt solutions.

Even though the composition of the solution was the major factor influencing fibre diameter, varying the parameters also had an effect on the process and fibre diameters. Increase in distance typically reduced fibre diameter when electric field strength remained constant. A longer distance is preferable since shorter distance also increased the likelihood of solution dripping onto the substrate and the occurrence of beaded fibres. At the lower end of the electric field strength range used in our study, we observed dripping and also a low production rate. At the higher end of the range, we observed 3D structures and the occurrence of larger fibres and micro range droplets on the web. Hence intermediate field strength seems optimal.

\section{Acknowledgements}

This work was carried out within the MARAPOKE project funded by Tekes (Finnish Funding Agency for Technology and Innovation) and the project consortium. Research partners in the project are VTT, TUT, Helsinki University of Technology and Åbo Akademi University. Industrial partners include Ahlstrom Glassfibre Oy, Beneq Oy, Outokumpu Oyj and Premix Oy.

\section{References}

[1] Reneker D. H., Chun I.: Nanometre diameter fibres of polymer, produced by electrospinning. Nanotechnology, 7, 216-223 (1996).

DOI: $10.1088 / 0957-4484 / 7 / 3 / 009$

[2] Li D., Xia Y.: Electrospinning of nanofibers: Reinventing the wheel? Advanced Materials, 16, 11511170 (2004).

DOI: $10.1002 / \mathrm{adma} .200400719$
[3] Reneker D. H., Fong H.: Polymeric nanofibers. ACS Symposium Series, Washington (2006).

[4] Ramakrishna S., Fujihara K., Teo W-E., Yong T., Ma Z., Ramaseshan R.: Electrospun nanofibers: Solving global issues. Materials Today, 9, 40-50 (2006). DOI: $10.1016 /$ S1369-7021(06)71389-X

[5] Greiner A., Wendorff J. H.: Electrospinning: A fascinating method for the preparation of ultrathin fibers. Angewandte Chemie International Edition, 46, 5670 5703 (2007). DOI: $10.1002 /$ anie.200604646

[6] Zuo W., Zhu M., Yang W., Yu H., Chen Y., Zhang Y.: Experimental study on relationship between jet instability and formation of beaded fibers during electrospinning. Polymer Engineering and Science, 45, 704 709 (2005). DOI: $10.1002 /$ pen.20304

[7] Deitzel J. M., Kleinmeyer J., Harris D., Beck Tan N. C.: The effect of processing variables on the morphology of electrospun nanofibers and textiles. Polymer, 42, 261-272 (2001). DOI: $10.1016 / \mathrm{S} 0032-3861(00) 00250-0$

[8] Heikkilä P.: Nanostructured fibre composites and materials for air filtration. $\mathrm{PhD}$ thesis, Tampere University of Technology (2008).

[9] Lin T., Wang H., Wang H., Wang X., Brenner M. P.: The charge effect of cationic surfactants on the elimination of fibre beads in the electrospinning of polystyrene. Nanotechnology, 15, 1375-1381 (2004). DOI: $\underline{10.1088 / 0957-4484 / 15 / 9 / 044}$

[10] Hohman M. M., Shin M., Rutledge G., Brenner M. P.: Electrospinning and electrically forced jets. I. Stability theory. Physics of Fluids, 13, 2201-2220 (2001). DOI: $\underline{10.1063 / 1.1383791}$

[11] Hohman M. M., Shin M., Rutledge G.: Electrospinning and electrically forced jets. II. Applications. Physics of Fluids, 13, 2221-2236 (2001). DOI: $\underline{10.1063 / 1.1384013}$

[12] Reneker D. H., Yarin A. L., Fong H., Koombhongse S.: Bending instability of electrically charged liquid jets of polymer solutions in electrospinning. Journal of Applied Physics, 87, 4531-4547 (2000). DOI: $10.1063 / 1.373532$

[13] Yarin A. L., Koombhongse S., Reneker D. H.: Bending instability in electrospinning of nanofibers. Journal of Applied Physics, 89, 3018-3026 (2001). DOI: $10.1063 / 1.1333035$

[14] Kim G. M., Lach R., Michler G. H., Poetschke P., Albrecht K.: Relationships between phase morphology and deformation mechanisms in polymer nanocomposite nanofibres prepared by an electrospinning process. Nanotechnology, 17, 963-972 (2006). DOI: $10.1088 / 0957-4484 / 17 / 4 / 021$

[15] Dersch R., Steinhart M., Boudriot U., Greiner A., Wendorff J. H.: Nanoprocessing of polymers: Applications in medicine, sensors, catalysis, photonics. Polymers for Advanced Technologies, 16, 276-282 (2005). DOI: $10.1002 /$ pat.568 
[16] Ye H., Lam H., Titchenal N., Gogotsi Y., Ko F.: Reinforcement and rupture behavior of carbon nanotubespolymer nanofibers. Applied Physics Letters, 85, 1775-1777 (2004).

DOI: $10.1063 / 1.1787892$

[17] Wan Y-Q., He J-H., Yu J-Y.: Carbon nanotube-reinforced polyacrylonitrile nanofibers by vibration-electrospinning. Polymer International, 56, 1367-1370 (2007).

DOI: $10.1002 /$ pi.2358

[18] Pan C., Ge L-Q., Gu Z-Z.: Fabrication of multi-walled carbon nanotube reinforced polyelectrolyte hollow nanofibers by electrospinning. Composites Science and Technology, 67, 3271-3277 (2007).

DOI: $\underline{10.1016 / \mathrm{j} . c o m p s c i t e c h .2007 .03 .036}$

[19] Lam H., Titchenal N., Naguib N., Ye H., Gogotski Y., Ko F.: Electrospinning of carbon nanotubes reinforced nanocomposite fibrils and yarns. Materials Research Society Symposium Proceeding, 791, 353-358 (2004).

[20] Seoul C., Kim Y-T., Baek C-K.: Electrospinning of poly(vinylidene fluoride)/ dimethylformamide solutions with carbon nanotubes. Journal of Polymer Science Part B: Polymer Physics, 41, 1572-1577 (2003). DOI: $10.1002 /$ polb.10511

[21] Park S. H., Jo S. M., Kim D. Y., Lee W. S., Kim B. C.: Effects of iron catalyst on the formation of crystalline domain during carbonization of electrospun acrylic nanofiber. Synthetic Metals, 150, 265-270 (2005). DOI: $10.1016 /$ j.synthmet.2005.02.010

[22] Jeong J. S., Jeon S. Y., Lee T. Y., Park J. H., Shin J. H., Alegaonkar P. S., Berdinsky A. S., Yoo J. B.: Fabrication of MWNTs/nylon conductive composite nanofibers by electrospinning. Diamond and Related Materials, 15, 1839-1843 (2006).

DOI: 10.1016/j.diamond.2006.08.026

[23] Ra E. J., An K. H., Kim K. K., Jeong S. Y., Lee Y. H.: Anisotropic electrical conductivity of MWCNT/PAN nanofiber paper. Chemical Physics Letters, 413, 188-193 (2005).

DOI: $10.1016 /$ j.cplett.2005.07.061

[24] Ju Y-W., Choi G-R., Jung H-R., Lee W-J.: Electrochemical properties of electrospun PAN/MWCNT carbon nanofibers electrodes coated with polypyrrole. Electrochimica Acta, 53, 5796-5803 (2008).

DOI: $10.1016 /$ j.electacta.2008.03.028

[25] Vaisman L., Wachtel E., Wagner H. D., Marom G.: Polymer-nanoinclusion interactions in carbon nanotube based polyacrylonitrile extruded and electrospun fibers. Polymer, 48, 6843-6854 (2007). DOI: $10.1016 /$ j.polymer.2007.09.032

[26] Prilutsky S., Zussman E., Cohen Y.: The effect of embedded carbon nanotubes on the morphological evolution during the carbonization of poly(acrylonitrile) nanofibers. Nanotechnology, 19, 165603/1165603/9 (2008).

DOI: $10.1088 / 0957-4484 / 19 / 16 / 165603$
[27] Dror Y., Salalha W., Khalfin R. L., Cohen Y., Yarin A. L., Zussman E.: Carbon nanotubes embedded in oriented polymer nanofibers by electrospinning. Langmuir, 19, 7012-7020 (2003).

DOI: $10.1021 / 1 \mathrm{a} 034234 \mathrm{i}$

[28] Yeo L. Y., Friend J. R.: Electrospinning carbon nanotube polymer composite nanofibers. Journal of Experimental Nanoscience, 1, 177-209 (2006). DOI: $\underline{10.1080 / 17458080600670015}$

[29] Hou H., Ge J. J., Zeng J., Li Q., Reneker D. H., Greiner A., Cheng S. Z. D.: Electrospun polyacrylonitrile nanofibers containing a high concentration of well-aligned multiwall carbon nanotubes. Chemistry of Materials, 17, 967-973 (2005).

DOI: $\underline{10.1021 / \mathrm{cm} 0484955}$

[30] Qin X-H., Yang E-L., Li N., Wang S-Y.: Effect of different salts on electrospinning of polyacrylonitrile (PAN) polymer solution. Journal of Applied Polymer Science, 103, 3865-3870 (2007).

DOI: $10.1002 / a p p .25498$

[31] Lin T., Wang H., Wang H., Wang X.: The effect of surfactants on the formation of fibre beads during the electrospinning of polystyrene nanofibres. in 'Polymer Fibres 2004, Meetings management' Manchester, UK, p4 (2004).

[32] Haghi A. K., Akbari M.: Trends in electrospinning of natural nanofibers. Physica Status Solidi A: Applications and Materials Science, 204, 1830-1834 (2007). DOI: $\underline{10.1002 / p s s a .200675301}$

[33 ] Seo J. M., Arumugam G. K., Khan S., Heiden P. A.: Comparison of the effects of an ionic liquid and triethylbenzylammonium chloride on the properties of electrospun fibers, 1-Poly(lactic acid). Macromolecular Materials and Engineering, 294, 35-44 (2009). DOI: $10.1002 /$ mame. 200800198

[34] Arumugam G. K., Khan S., Heiden P. A.: Comparison of the effects of an ionic liquid and other salts on the properties of electrospun fibers, 2-Poly(vinyl alcohol). Macromolecular Materials and Engineering, 294, 4553 (2009).

DOI: $10.1002 / \mathrm{mame} .200800199$

[35] Mathew G., Hong J. P., Rhee J. M., Lee H. S., Nah C.: Preparation and characterization of properties of electrospun poly(butylene terephthalate) nanofibers filled with carbon nanotubes. Polymer Testing, 24, 712-717 (2005).

DOI: $10.1016 /$ j.polymertesting.2005.05.002

[36] Heikkilä P., Harlin A.: Parameter study of electrospinning of polyamide-6. European Polymer Journal, 44, 3067-3079 (2008).

DOI: $10.1016 /$ j.eurpolymj.2008.06.032

[37] Morton W. J.: Method of dispensing fluids. US Patent 705691, USA (1902).

[38] Baumgarten P. K.: Electrostatic spinning of acrylic microfibers. Journal of Colloid and Interface Science, 36, 71-79 (1971). 
[39] He J-H., Wan Y-Q., Yu J-Y.: Effect of concentration on electrospun polyacrylonitrile (PAN) nanofibers. Fibers and Polymers, 9, 140-142 (2008).

DOI: $10.1007 / \mathrm{s} 12221-008-0023-3$

[40] Gu S. Y., Ren J., Wu Q. L.: Preparation and structures of electrospun PAN nanofibers as a precursor of carbon nanofibers. Synthetic Metals, 155, 157-161 (2005).

DOI: $10.1016 /$ j.synthmet.2005.07.340

[41] Gu S. Y., Ren J., Vancso G. J.: Process optimization and empirical modeling for electrospun polyacrylonitrile (PAN) nanofiber precursor of carbon nanofibers. European Polymer Journal, 41, 2559-2568 (2005). DOI: $10.1016 /$ j.eurpolymj.2005.05.008

[42] Zussman E., Chen X., Ding W., Calabri L., Dikin D. A., Quintana J. P., Ruoff R. S.: Mechanical and structural characterization of electrospun PAN-derived carbon nanofibers. Carbon, 43, 2175-2185 (2005). DOI: $10.1016 /$ j.carbon.2005.03.031
[43] Sutasinpromprae J., Jitjaicham S., Nithitanakul M., Meechaisue C., Supaphol P.: Preparation and characterization of ultrafine electrospun polyacrylonitrile fibers and their subsequent pyrolysis to carbon fibers. Polymer International, 55, 825-833 (2006).

DOI: $10.1002 / \mathrm{pi} .2040$

[44] Agend F., Naderi N., Fareghi-Alamdari R.: Fabrication and electrical characterization of electrospun polyacrylonitrile-derived carbon nanofibers. Journal of Applied Polymer Science, 106, 255-259 (2007). DOI: 10.1002/app.26476

[45] Saiyasombat C., Maensiri S.: Fabrication, morphology, and structure of electrospun PAN-based carbon nanofibers. Journal of Polymer Engineering, 28, 5-18 (2008).

[46] Heikkilä P., Harlin A.: Electrospun nanofibres containing carbon nanotubes. in 'Autex 2008, $8^{\text {th }}$ Annual World Textile Conference’Biella, Italy, p6 (2008). 